Article

\title{
Incorporating Liquid Crystal Display (LCD) Glass Waste as Supplementary Cementing Material (SCM) in Cement Mortars-Rationale Based on Hydration, Durability, and Pore Characteristics
}

\author{
Seong Kyum Kim ${ }^{1}\left(\mathbb{D}\right.$, Asad Hanif $^{2} \mathbb{D}$ and Il Young Jang ${ }^{3, *}$ \\ 1 Research Institute for Mega Structures, Korea University, Seoul 02841, Korea; envylife@korea.ac.kr \\ 2 Department of Civil Engineering, Mirpur University of Science and Technology (MUST), Allama Iqbal Road \\ Mirpur AJ \& K 10250, Pakistan; ahanif@connect.ust.hk \\ 3 Department of Civil Engineering, Kumoh National Institute of Technology, Gumi 39177, Korea \\ * Correspondence: jbond@kumoh.ac.kr
}

Received: 29 November 2018; Accepted: 11 December 2018; Published: 13 December 2018

\begin{abstract}
This paper assesses the feasibility of using liquid crystal display (LCD) waste glass as a supplementary cementing material in cement mortars. Two different sizes of LCD waste glass powder (LGP) particles were used (5 $\mu \mathrm{m}$ and $12 \mu \mathrm{m})$ with two substitution levels with cement in mortar $(10 \%$ and $20 \%$ ). The resulting mortars were evaluated for strength, hydration, porosity and durability through various experimental techniques. It was found that LGP particles lead to appreciable strength gain at all ages in comparison with control mortar, especially significant strength gain of $18 \%$ was observed at 28-day. This is attributed to the greater gel-space ratio as corroborated by the experimental determination of porosity, which is found less for LGP-incorporated mortars as compared to control cement mortar. The smaller particle size of LGPs not only accelerates the pozzolanic reaction in alkaline cementitious matrix, but also fills the smaller pores, thus reducing porosity and contributing to strength gain. Increased hydration was also elucidated qualitatively by backscattered electron imaging. Due to the increased hydration in LGP-incorporated pastes and mortars, the durability (in terms of chloride ion permeability) has also been found improved. Thus, it is established that $10 \%$ (by weight) of cement can be replaced with $12 \mu \mathrm{m}$ LGP, whereas $20 \%$ can be replaced with $5 \mu \mathrm{m}$ LDP for improved strength and durability. Incorporating LCD waste in mortars and concretes as partial replacement of cement can not only help utilize this potentially hazardous waste, but also significantly reduce the associated carbon dioxide emissions, thus promoting sustainable development.
\end{abstract}

Keywords: LCD; cement mortar; SCM; hydration characteristics; porosity

\section{Introduction}

Concrete is the most widely used man-made material on earth. Its annual production is in billions of tons worldwide [1]. Cement, being the primary ingredient in concrete production, is, thus, produced in huge quantities, resulting in emissions of greenhouse gases to the environment. It is estimated that a metric ton of cement production results in emission of $931 \mathrm{~kg}$ of carbon dioxide in the environment [2,3]. Thus, from a sustainability point of view, cement consumption must be restricted either by using alternate binders such as magnesium phosphate cement [4], magnesium oxychloride cement [5], calcium sulfo-aluminate cement [6] and geopolymers [7,8], or incorporating pozzolanic materials as supplementary cementing material in concretes such as fly ash [9], silica fume [10], slag [11,12], metakaolin [13], rice husk ash [14], waste glass powder [15], etc. Another way is to incorporate different waste materials as aggregates in lieu of normal aggregates in concrete, like 
recycled aggregate concrete [3,16,17], ceramic waste [18-20], or crushed bricks [21]. Another potentially suitable material for use as supplementary cementing material (SCM) is liquid crystal display (LCD) glass waste, which has been investigated by a few researchers in recent years [22-25].

LCD waste glass is generated in tremendous amounts, owing to the development of the electronic display industry. With the increasing demand for handheld devices worldwide, LCD production is expected to grow exponentially, leading to increased LCD waste generation. While LCD glass is composed of silica, alumina and alkaline earth oxides, it differs largely from traditional glass [25]. LCD waste glass is usually divided into three classes: LCD cullet, LCD waste glass, and end-of-life LCD waste glass [26]. Such e-waste is potentially hazardous in many ways, owing to its non-degradability and toxic nature (due to its composition), thus creating hazards during disposal [27,28].

The current study focuses on LCD waste glass generated from LCD manufacturers due to defects in processing and cutting or bonding in the LCD panels. These defective LCD panels contain trace amounts of elements such as copper, manganese, molybdenum, and iron, and cannot be recycled due to extremely intricate recycling processes. Even if they are recycled, the resulting quality is degraded, making them unfit for customer use; thus, such panels are discarded in landfills. In 2015, around 40,000 tons of LCD glass panels were wasted in Korea alone [29].

Although a large number of studies on waste glass use as SCM have been conducted, research findings to substantiate LCD glass panel waste are sparse. The use of LCD waste glass as fine aggregate in concrete is well corroborated and it is shown that $20 \%$ sand can be replaced with LCD waste glass powder (LGP) [30,31]. It has also been shown earlier that LGP use as sand replacement can lead to improved durability [32] and better fire resistance [33]. A few studies conducted earlier also tried to use it as a supplement to binder. For instance, thin film transistor (TFT) LCD waste glass was used as SCM in concrete: $10 \%$ substitution was determined as optimal [34]. Further, TFT-LCD based binder pastes were formulated and the resulting hydration attributes were corroborated by thermal analyses [35]. It was also verified that cement-based composites (mortars and concretes), as well as ceramics can properly incorporate such waste without appreciable loss in strength and other properties [36].

Although the use of LCD glass panel waste as SCM in concrete and mortars has been studied, its detailed hydration attributes have not been investigated. This paper corroborates the use of LGP as partial replacement of cement in mortars by evaluating its strength, hydration, durability and porosity. A few studies published earlier have either only used LGP as a fine aggregate or have focused only on its compressive strength and hydration based on thermal analyses. This paper is novel because it investigates the durability of cement mortars, as well as innovatively corroborates the pozzolanic reaction of LGP in an alkaline cementitious matrix by using backscattered electron image analysis.

\section{Materials and Experimental Methods}

\subsection{Materials Characterization}

Ordinary Portland Cement (OPC) complying with KSL 5201 [37] was used as a primary binder in this experimental study. Standard quartz sand (fineness modulus; 2.92; water absorption; $2.40 \%$, unit weight; $1597 \mathrm{~kg} / \mathrm{m}^{3}$; specific gravity; 2.60 , and $2.2 \%$ particles passing through \#200 sieve) was used as fine aggregate in preparing the mortar specimens. The tests were conducted in accordance with Korean standards [38-40] and adopted in [41].

LCD glass waste was obtained from Inno. Co. Ltd., Daegu, Korea. Two different types of LGP were prepared by grinding the glass in ball mills (mean particle size $5 \mu \mathrm{m}$ and $12 \mu \mathrm{m}$ ). The detailed material characterization results are shown in Figures 1-3 and Table 1. The specific surface area of LCD particles was determined by the BET method [25] (Beckman Coulter SA3100 surface area and pore size analyzer, Brea, CA, USA). It can be seen from Table 1 that the mean particle size and surface area of LGP are comparable to OPC, and the chemical analysis indicates presence of both silica and lime. This hypothesizes the pozzolanic reaction of LGP in an alkaline cementitious matrix. However, the reactivity of LGP can be corroborated by X-Ray Diffraction (XRD), which is done on the Bruker 
advance-D8 power diffractometer (Billerica, MA, USA) with Cu-Ka radiation $(\lambda=0.154,178 \mathrm{~nm})$ by subjecting the LGP particles to X-rays at a scanning rate of $10^{\circ} / \mathrm{min}$ [26]. The broad hump in XRD diffractogram elucidates the amorphous nature of silica present in LGP; thus, it can react with calcium hydroxide and lead to formation of secondary hydrates [15,42,43].

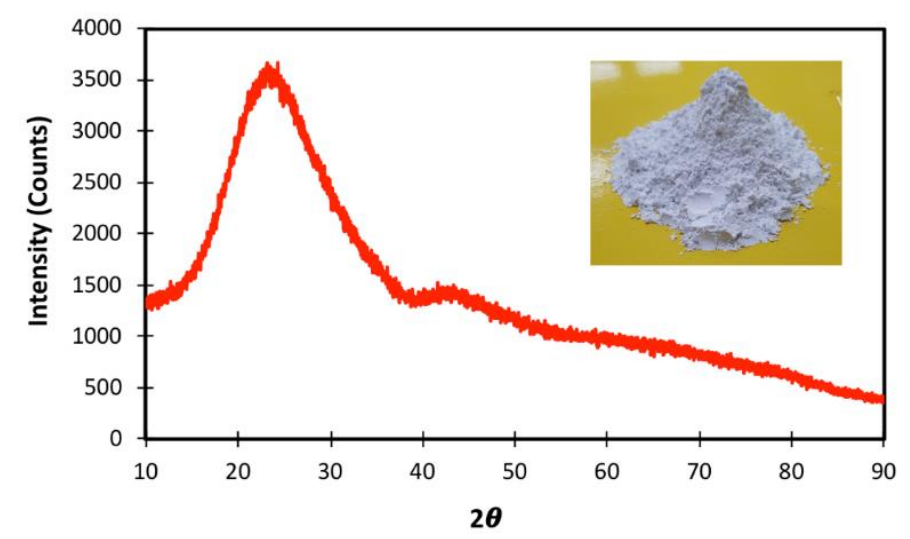

Figure 1. XRD of LGP particles.
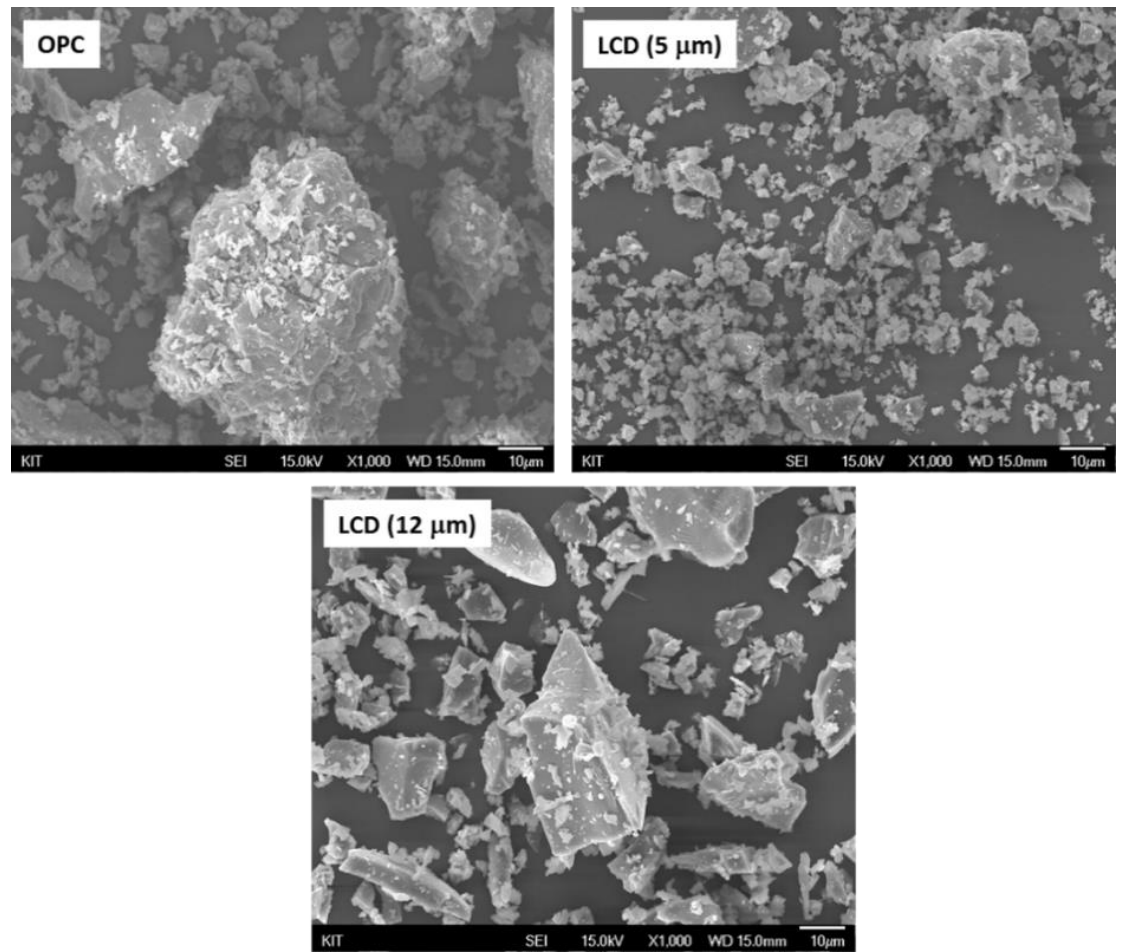

Figure 2. SEM images of raw material particles.

Table 1. Physical and chemical properties of raw materials used in the study.

\begin{tabular}{|c|c|c|c|c|c|c|c|c|c|}
\hline \multirow{2}{*}{ Binder } & \multirow{2}{*}{$\begin{array}{l}\text { Mean Size } \\
\quad(\mu \mathrm{m})\end{array}$} & \multirow{2}{*}{$\begin{array}{l}\text { Surface Area } \\
\left(\mathrm{m}^{2} / \mathrm{g}\right)\end{array}$} & \multicolumn{7}{|c|}{ Oxide Composition (\%) } \\
\hline & & & $\mathrm{MgO}$ & $\mathrm{Al}_{2} \mathrm{O}_{3}$ & $\mathrm{SiO}_{2}$ & $\mathrm{CaO}$ & $\mathrm{Fe}_{2} \mathrm{O}_{3}$ & $\mathrm{SO}_{3}$ & $\mathrm{~K}_{2} \mathrm{O}$ \\
\hline OPC & 21 & 1.288 & 2.84 & 4.04 & 19.0 & 65.1 & 3.09 & 3.77 & 1.570 \\
\hline \multirow{2}{*}{ LCD } & 5 & 0.996 & 0.4 & 18.2 & 66.9 & 10.0 & 0.08 & - & 0.057 \\
\hline & 12 & 0.935 & 0.42 & 18.0 & 65.7 & 10.3 & 0.14 & - & 0.044 \\
\hline
\end{tabular}




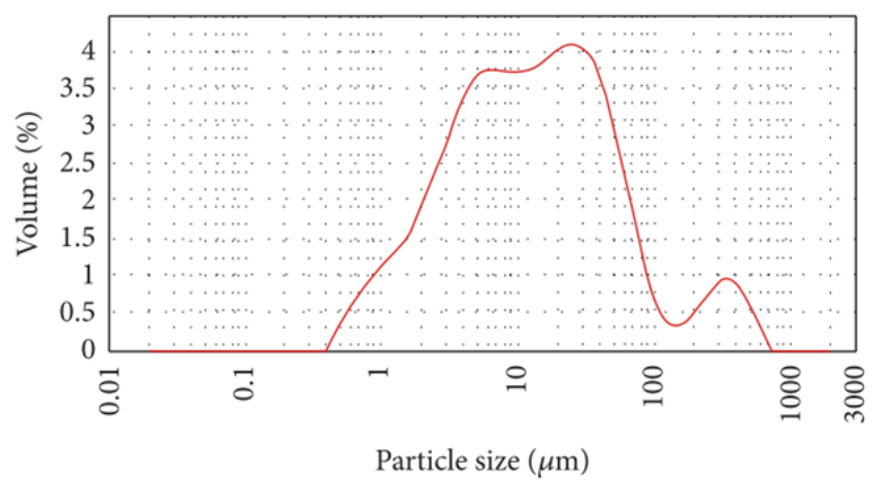

(a)

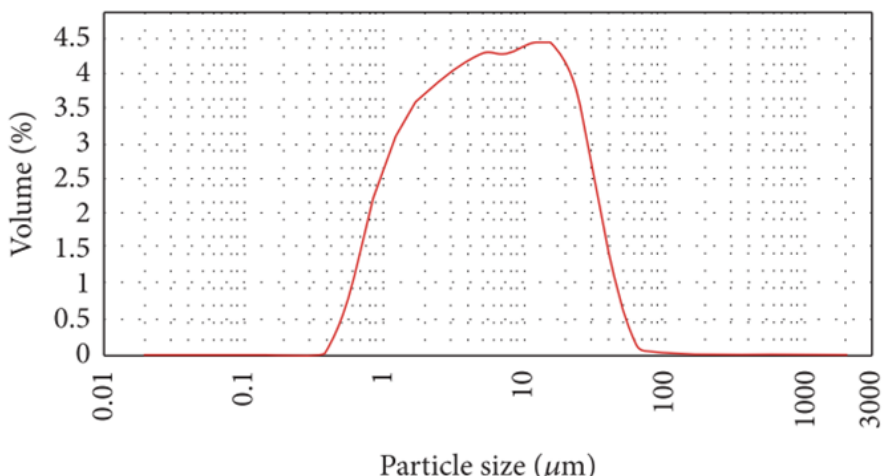

(b)

Figure 3. Particle size distribution (done by laser granulometry) of (a) LGP12, and (b) LGP5.

\subsection{Mixture Proportioning and Specimens Casting}

The objective of this study was to determine the suitability of LGP as SCM; therefore, it was substituted for cement in the mortars. Two substitution levels viz-a-viz 10\% and 20\% (by binder weight) were used. The substitution level was decided on the basis of available findings for other SCMs such as metakaolin, silica fume, etc., which have shown that any replacement level higher than $20 \%$ is detrimental to strength attributes of the hardened mortars and concretes [13,44]. The mix proportion (by weight) was selected as 1:0.4:2.13 binder (OPC + LGP), water, and sand. As the prime objective in this study was to determine the influence of LCD glass waste in water, the weight fraction of sand was not significant, as long as it was kept the same in all mix proportions [44]. The mixing regime comprised of dry mixing of all the powders and sand, followed by addition of required water and subsequent additional mixing until the achievement of a uniform consistent mix, observed through visual inspection. $50 \mathrm{~mm}$ side mortar cubes were cast for compressive strength testing and chloride penetration. In addition, pure binder paste samples (without sand) with a fixed water to binder ratio of 0.40 were also cast (cubes of $40 \mathrm{~mm}$ side) for evaluating the hydration attributes through backscattered electron imaging (BSE). The water-to-binder ratio for all the specimens were fixed at 0.40 to have a fair comparison of properties. The casted samples were covered with a polyethene sheet to prevent moisture loss, and subsequently demolded and put in a moist cabinet (at $25^{\circ} \mathrm{C}$ temperature and $95 \%$ relative humidity) for curing until the desired testing age. 


\subsection{Experimental Methods and Procedures}

\subsubsection{Compressive Strength Testing}

Compressive strength was carried out on mortar cubes of $50 \mathrm{~mm}$ in accordance with American Society of Testing and Materials (ASTM) C109 [45]. The specimens were tested at various ages of 7 days, 28 days, and 56 days.

\subsubsection{Chloride Diffusion}

The resistance to chloride ion penetration for LCD mortar with 28 days of curing was investigated in compliance with the Rapid Chloride Ion Penetration Test (RCPT) NT BUILD 443 [12,15,46,47] in which the specimens were exposed to $0.5 \mathrm{M} \mathrm{NaCl}$. The increment of profile was $2 \mathrm{~mm}$ over $40 \mathrm{~mm}$ of penetration depth. By fitting the total chloride concentration profiles to the error function for chloride diffusion, regression parameters (i.e., surface chloride content and apparent chloride diffusion coefficient) were obtained:

$$
C(x, t)=C_{s}\left(1-\operatorname{erf}\left(\frac{x}{\sqrt{4 D t}}\right)\right)
$$

where ' $C$ ' is the chloride concentration (\% by sample weight), ' $C_{s}$ ' is the surface chloride concentration (\% by sample weight), $t$ is the exposure time (sec), ' $D$ ' is the apparent diffusion coefficient $\left(\mathrm{m}^{2} / \mathrm{s}\right.$ ).

\subsubsection{Porosity and Pore Size Distribution}

The porosity and pore volume characteristics of the pastes were studied by Mercury Intrusion Porosimetry (MIP, Micromeritics' AutoPore IV 9500 Series, Norcross, GA, USA). Samples for MIP were taken from the fractured compressive strength specimens. Chunks of mortars were crushed to smaller pieces and pore water was removed by the solvent replacement method, with isopropanol as the solvent. The detailed experimental method is covered in [42,48-52].

\subsubsection{Backscattered Electron (BSE) Image Analysis}

BSE was done on MIRA3 TESCAN (Brno-Kohoutovice, Czech Republic), SEM HV: $15 \mathrm{kV}$, Magnification: $500 \times$, View field: $413 \mu \mathrm{m} \times 550 \mu \mathrm{m}$, Resolution: $0.5376 \mu \mathrm{m}$ per pixel, WD: $10 \mathrm{~mm}$, grayscale of BSE image: 0-255. For BSE, only the binder pastes were considered in order to determine the degree of hydration. The reason for choosing a binder paste as the test sample is to minimize the effects of aggregate inclusion, which may impose disruption in image processing due to silicate components in the aggregate. Thin sections of 5-10 $\mathrm{mm}$ were cut, and the free water was removed by immersing them in isopropanol. Then, the slices were saturated with resin, to support the microstructure, followed by polishing by abrasive papers of various grit sizes to achieve a smooth surface. The detailed polishing method, as used in the work of Hu and Li [53-55], was adopted. "The polishing of the sample is particularly critical for image analysis, as imperfections induced by polishing may cause problems during the segmentation of grains." [56]. Later, the samples were carbon-coated for onward testing using an electron microscope. The samples were tested at the age of 7,14 , and 28 days. The porosity was determined by dividing the pore area by the total area, while the hydration degree was quantified by dividing the area of hydrated products by the total area of hydrated and un-hydrated products. The resulting values were shown in terms of corresponding percentages. The upper threshold grey level for porosity is determined from the inflection point of the cumulative brightness histogram of the BSE image. This represents a critical point where a small incremental grey value causes a sudden increase in threshold area, a condition termed as overflow [57]. The detailed methodological description is covered in great length in previously published literature $[57,58]$. 


\section{Results, Discussion, and Analyses}

\subsection{Compressive Strength}

The results for compressive strength are given in Figure 4. Typical behavior of cement-based composites of increasing strength with increase in curing age can be clearly seen. Further, the positive effect of LGP on strength enhancement is also obvious, particularly at 28 days, which is in agreement with the work of Kim et al. [37]. It is, however, important to point out the effect of particle size on the achieved strength.

The finer particles tend to involve more expressively in pozzolanic reactions [44,59], resulting in the formation of calcium silicate hydrate gel (reaction of calcium hydroxide present in the hydrated cement paste with the amorphous silica of LGP); their pore-filling effect is also well known $[49,60]$. Thus, in effect, the void ratio is reduced i.e., the gel-space is increased, resulting in increased compressive strength. At 7 days, age $5 \mu \mathrm{m}$ LGP particles showed up to $4 \%$ strength increment in comparison with the control mortar (containing no LGP), whereas the $20 \mu \mathrm{m}$ LGP particles showed a strength decline of $7.5 \%$ at the $20 \%$ replacement level, indicating their inertness and acting merely as fillers, though a meagre strength increase of $2 \%$ could be observed for 10\% substitution level. At age of 28 days, optimum performance of LGPs could be seen, where LGP- $5 \mu \mathrm{m}$ resulted in a maximum strength increase of $18 \%$. However, at 56 days, this increase was reduced to $13 \%$. After this age, the hydration progresses so meagerly that it marginally affects the strength disparity [61], hence it can be safely said up to $13 \%$ strength can be improved with LGP addition with finer particle diameter.

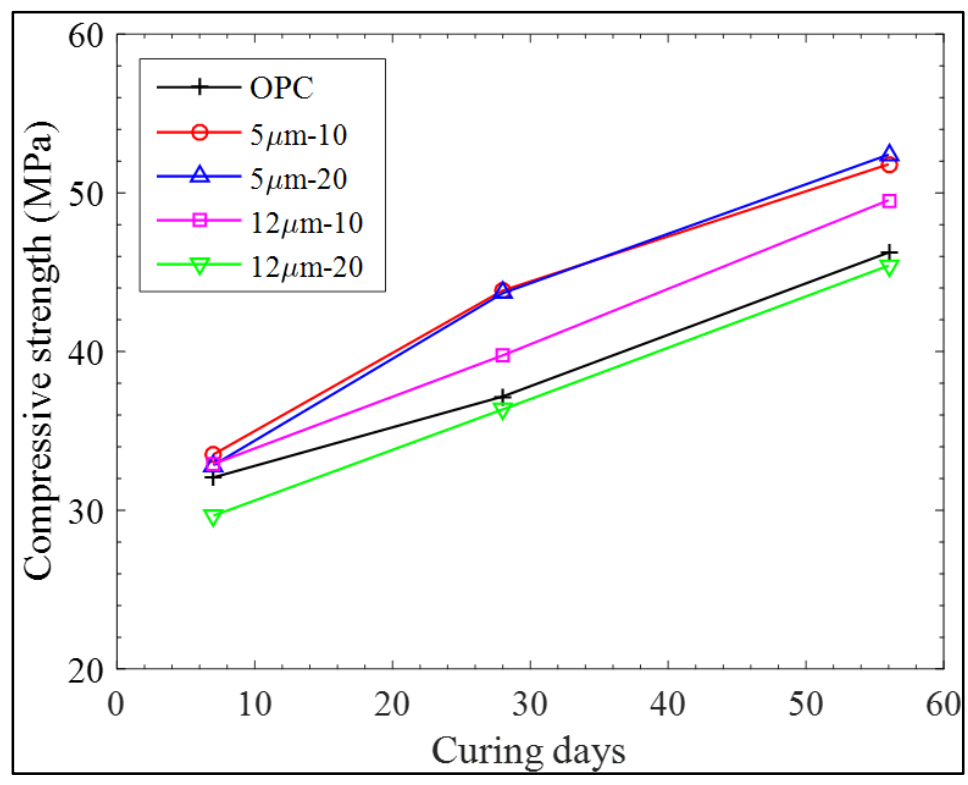

Figure 4. Compressive strength for LCD mortar at 7, 28, and 56 days.

\subsection{Porosity and Pore Size Distribution}

In order to verify the increased gel-space ratio in LGP incorporated mortars, porosity was determined, which is directly correlated to gel-space ratio. The results of porosity and pore size distribution are plotted in Figure 5. The pore size distribution curves from MIP show that all pastes had a predominantly unimodal distribution (i.e., only one maxima peak). At age of 7 days, LGP incorporation did not influence porosity significantly. However, at later ages, it was clearly observed that LGP incorporation led to prominent decrease in porosity.

It is also pertinent to specify the importance of distribution of pores within the matrix. "Materials with even the same porosity can perform completely differently because of size and dispersal of pores, in the matrix" [49,52]. In the log differential plot (Figure 5; plotted on secondary y-axis), the critical 
pore diameter $\left(\mathrm{d}_{\mathrm{c}}\right)$ and threshold pore diameter $\left(\mathrm{d}_{\mathrm{th}}\right)$ tended to shift towards the left, which is the lower pore size range. $d_{c}$ is calculated from the highest point of log differential plot, whereas $d_{t h}$ is identified from the slope of cumulative porosity plot. Substitution of cement with finer LGP particles $(5 \mu \mathrm{m}$ diameter) shifted these from a macro-pore zone to a meso-pore zone, resulting in finer pore structure. From the renowned strength-porosity relations [62], combined with the compressive strength results, the small differences are justifiable.
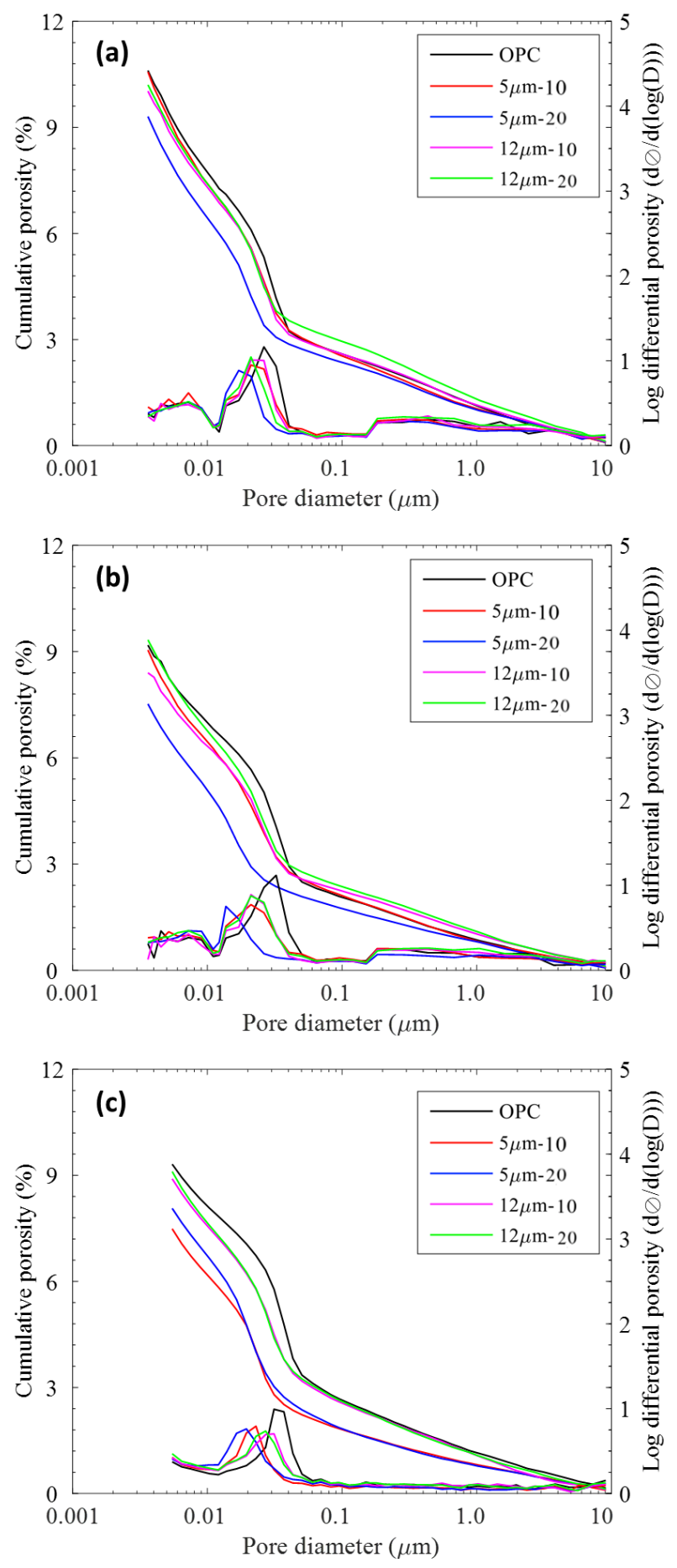

Figure 5. Cumulative porosity and log-differential porosity plots at (a) 7 days, (b) 14 days, and (c) 28 days. 
Bulk density and apparent (skeletal) density values were also obtained from MIP, which are reported in Table 2. LGP-incorporated mortars exhibited higher values of bulk and skeletal densities, except for LGP20, which signifies higher mechanical strength owing to a higher density of Calcium Slicate Hydrate (CSH) gel as compared to other hydration products [63]. This further substantiates that LGP incorporation leads to reduced air voids, thus improving mechanical properties.

Table 2. Bulk and skeletal densities obtained through MIP.

\begin{tabular}{ccccccc}
\hline \multirow{2}{*}{ Mix ID } & \multicolumn{2}{c}{ 7-Day Age } & \multicolumn{2}{c}{ 14-Day Age } & \multicolumn{2}{c}{ 28-Day Age } \\
\cline { 2 - 6 } & $\begin{array}{c}\text { Bulk Density } \\
\text { (g/cc) }\end{array}$ & $\begin{array}{c}\text { Skeletal } \\
\text { Density (g/cc) }\end{array}$ & $\begin{array}{c}\text { Bulk Density } \\
\text { (g/cc) }\end{array}$ & $\begin{array}{c}\text { Skeletal } \\
\text { Density (g/cc) }\end{array}$ & $\begin{array}{c}\text { Bulk Density } \\
\text { (g/cc) }\end{array}$ & $\begin{array}{c}\text { Skeletal } \\
\text { Density (g/cc) }\end{array}$ \\
\hline OPC & 2.123 & 2.475 & 2.159 & 2.453 & 2.120 & 2.425 \\
$5 \mu \mathrm{m}-10$ & 2.130 & 2.470 & 2.129 & 2.426 & 2.159 & 2.406 \\
$5 \mu \mathrm{m}-20$ & 2.087 & 2.382 & 2.094 & 2.344 & 2.152 & 2.411 \\
$12 \mu \mathrm{m}-10$ & 2.131 & 2.463 & 2.180 & 2.461 & 2.136 & 2.417 \\
$12 \mu \mathrm{m}-20$ & 2.059 & 2.392 & 2.070 & 2.360 & 2.109 & 2.393 \\
\hline
\end{tabular}

\subsection{Image Analysis for Porosity \& Degree of Hydration}

The results of BSE analysis are given in Figures 6 and 7 as well as tabulated in Table 3. The basic principle is that the volume fraction of a given phase is equal to the average surface fraction in a $2 \mathrm{D}$ microstructure, provided the number of sections analyzed is large enough to be statistically representative. Thresholding level between pore and solid is determined by finding the inflection point. The inflection point of the cumulative brightness histogram of a BSE image represents a critical transition where the segmented pore areas begin to 'overflow' to the surrounding paste [57]. All the curves shown in Figure 7 have a common value of inflection point (gray level 77), thereby used for the upper threshold level for all the paste samples. Thresholding levels between hydrated and un-hydrated products are 120,135, and 148 respectively for 7, 14, and 28 days. With the specified threshold levels, degree of hydrations for OPC paste are $50.76 \%, 56.25 \%, 62.91 \%$, respectively, for 7 , 14 , and 28 days. Those are equivalent to $51 \%, 56 \%, 62 \%$ at $0.4 \mathrm{w} / \mathrm{c}$ of OPC paste, respectively, for 7 , 14 , and 28 days [64]. It is to be clarified here that the results of porosity may differ in MIP and BSE because MIP was done on mortar specimens containing sand, whereas BSE was performed on binder pastes (justification is already presented earlier).

Table 3. Parameters obtained from BSE image analysis for cement pastes at various ages $\left({ }^{*}\right.$ the values indicate the average of porosity and hydration degree calculated from various frames in BSE imaging).

\begin{tabular}{|c|c|c|c|c|}
\hline \multirow{2}{*}{ Mix } & \multirow{2}{*}{ Parameter } & \multicolumn{3}{|c|}{ Average Values* } \\
\hline & & 7 Days (Age) & 14 Days (Age) & 28 Day (Age) \\
\hline \multirow{2}{*}{ OPC } & Porosity $(\%)$ & 19.31 & 6.37 & 9.88 \\
\hline & Hydration Degree (\%) & 50.76 & 56.25 & 62.91 \\
\hline \multirow{2}{*}{$5 \mu \mathrm{m}-10$} & Porosity $(\%)$ & 20.51 & 11.61 & 7.22 \\
\hline & Degree of Hydration (\%) & 43.76 & 61.72 & 67.11 \\
\hline \multirow{2}{*}{$5 \mu \mathrm{m}-20$} & Porosity $(\%)$ & 21.70 & 10.54 & 8.16 \\
\hline & Hydration Degree (\%) & 39.63 & 52.45 & 65.96 \\
\hline \multirow{2}{*}{$12 \mu \mathrm{m}-10$} & Porosity $(\%)$ & 22.36 & 7.57 & 6.51 \\
\hline & Hydration Degree (\%) & 42.42 & 60.65 & 69.04 \\
\hline \multirow{2}{*}{$12 \mu \mathrm{m}-20$} & Porosity $(\%)$ & 18.73 & 12.37 & 13.16 \\
\hline & Hydration Degree (\%) & 35.27 & 67.55 & 83.66 \\
\hline
\end{tabular}

For quantifying the degree of hydration, other methods such as XRD with Rietveld analysis, or Thermogravimetric Analysis (TGA) may be used which are faster as well as more accurate (the relative error on degree of hydration is about $5-10 \%$ by image analysis in comparison with only 
$2-3 \%$ by XRD-Rietveld analysis [58]). However, BSE offers better understanding of microstructural attributes like phase morphology, phase distribution, C-S-H density, and porosity.

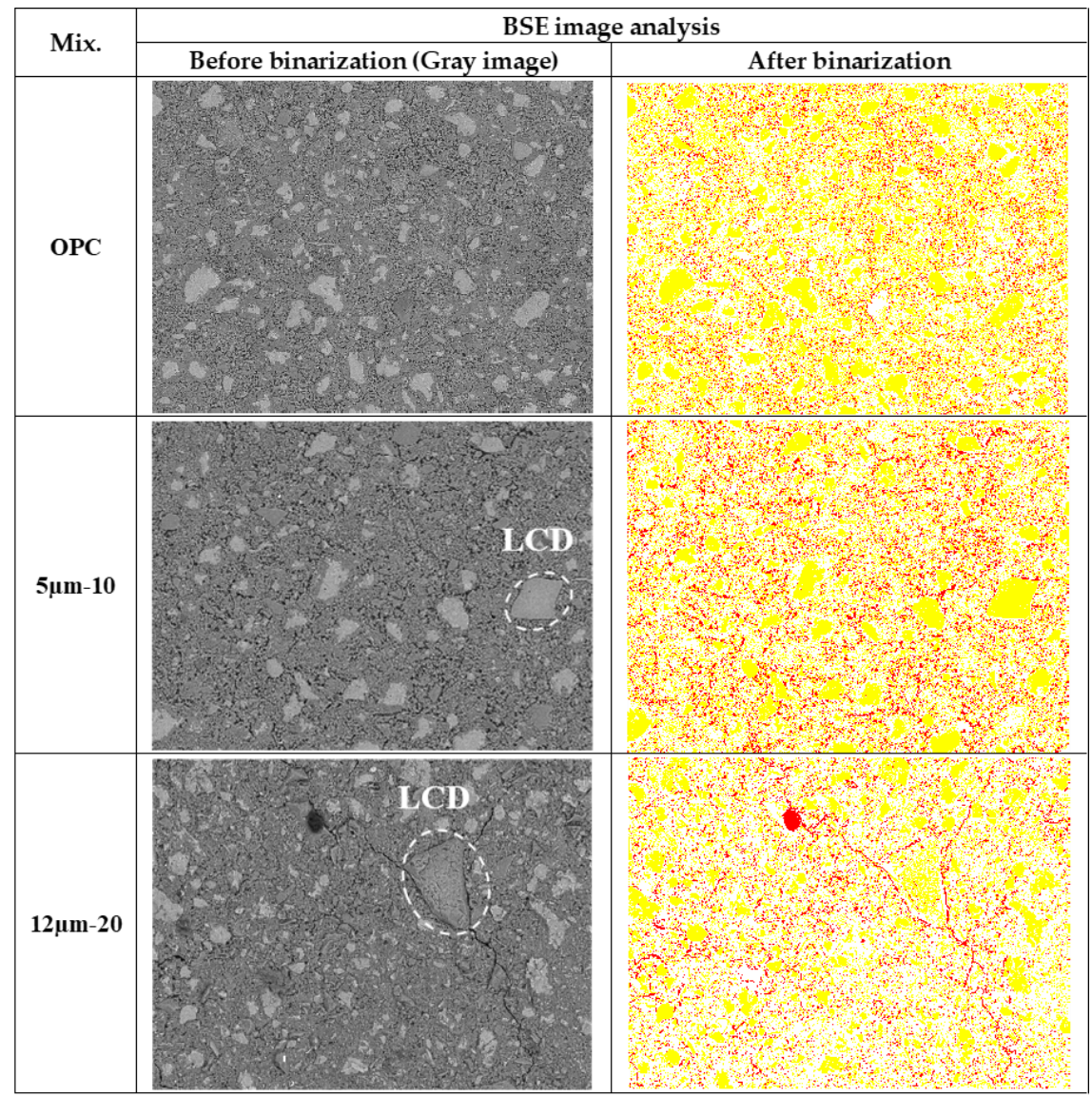

Figure 6. Example images before and after binarization for cement pastes at 14 days (pore: red, hydrated product: white, un-hydrated product: yellow).

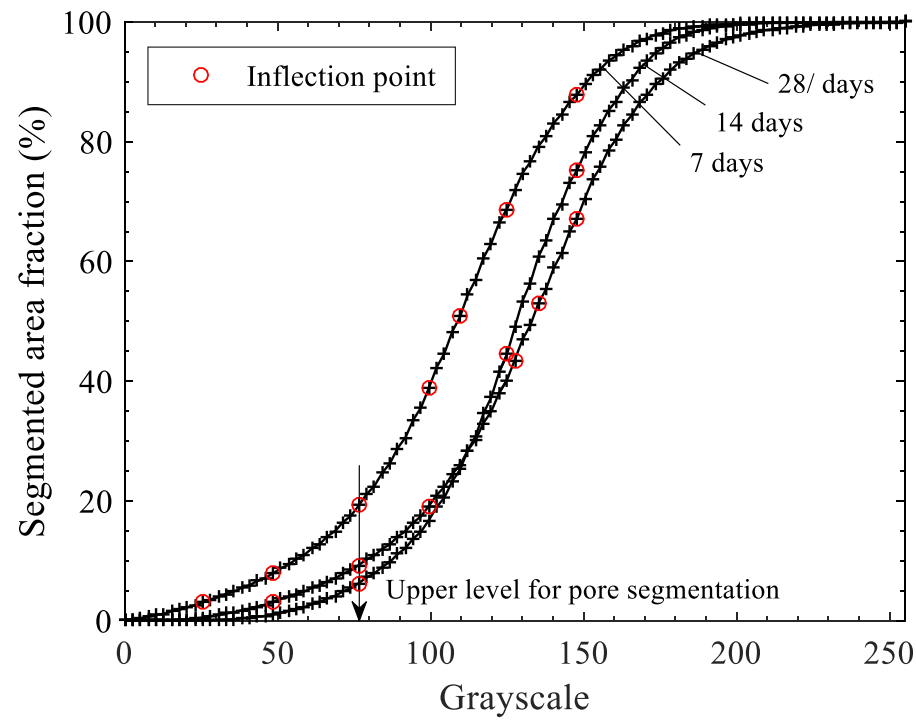

Figure 7. Determination of threshold level between pore and solid (OPC paste was used for the example). 


\subsection{Chloride Diffusion}

The results of chloride diffusion after 28 days are represented in Figure 8 and Table 4 . It was seen that $20 \%$ addition of LGP12 is detrimental to the mortars, as it increases the chloride content in the specimens after exposure to chloride salts. The $10 \%$ addition of either LGP (finer or coarser) led to improved durability properties indicated by the lower chloride content residing in the specimens at various depths, while $20 \%$ addition of LGP5 resulted in optimum results. Thus, it is quite evident from RCPT that the addition of LGP in cement mortars lead to better durability due to greater packing of solid phases in the matrix.
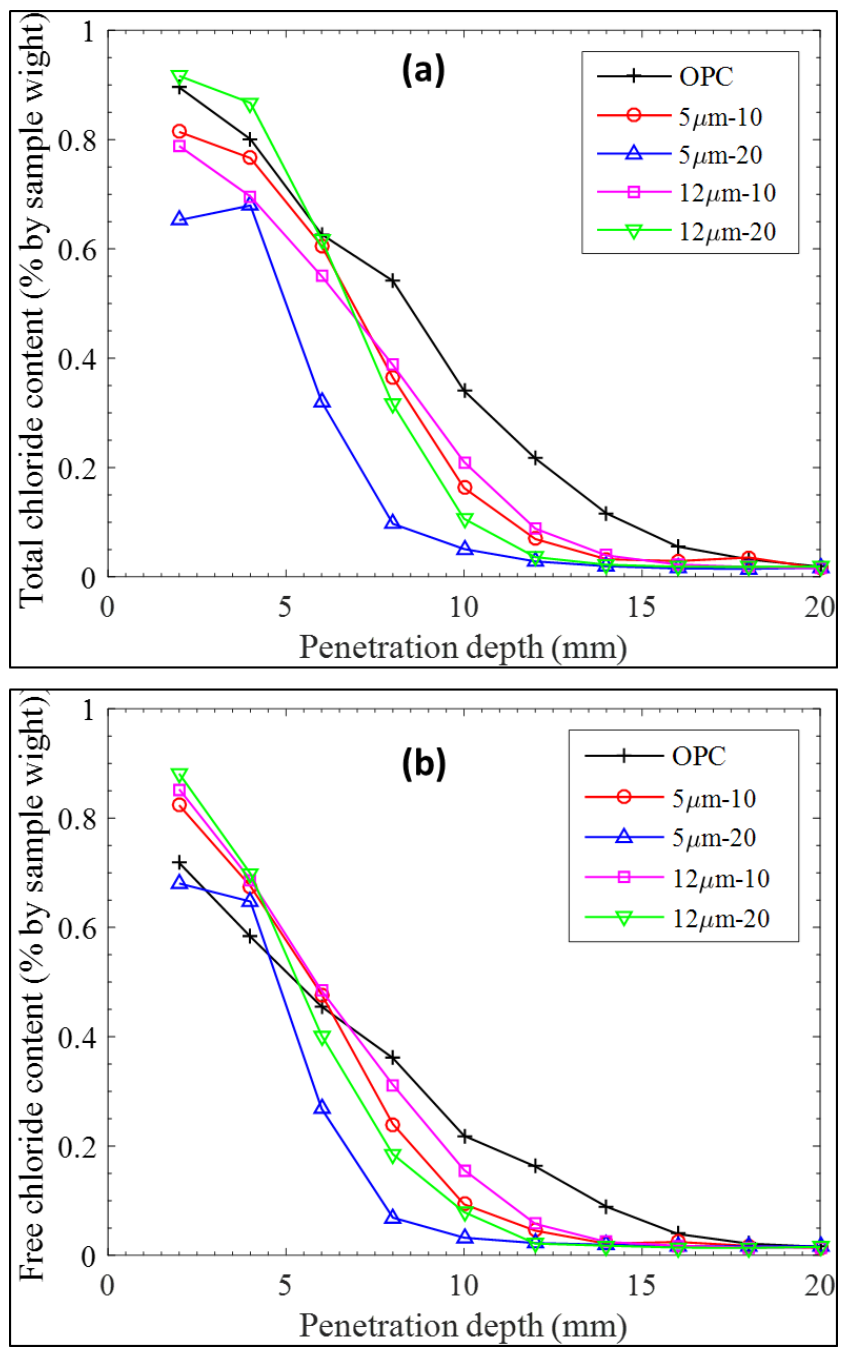

Figure 8. Concentration profiles for (a) free chloride, and (b) total chloride.

Table 4. Diffusion parameters obtained from the total chloride concentration profile.

\begin{tabular}{cccc}
\hline Mix & Cs (\% by Sample Weight) & $\boldsymbol{D}\left(\mathbf{E}-\mathbf{1 2} \mathbf{~ m}^{\mathbf{2}} \mathbf{s}\right)$ & R Squared \\
\hline OPC & 1.15 & 12.28 & 0.98 \\
$5 \mu \mathrm{m}-10$ & 1.14 & 8.24 & 0.96 \\
$5 \mu \mathrm{m}-20$ & 1.01 & 4.86 & 0.93 \\
$12 \mu \mathrm{m}-10$ & 1.06 & 8.98 & 0.97 \\
$12 \mu \mathrm{m}-20$ & 1.33 & 6.59 & 0.95 \\
\hline
\end{tabular}




\section{Inferences, Conclusions, and Prospects-A Way Forward}

In this study, the feasibility of LCD waste glass as partial replacement of cement was assessed through strength, hydration, and durability characteristics. LCD waste glass was milled and ground to finer particle sizes. Two types of LGP were used: one, with mean particle size of $5 \mu \mathrm{m}$, and other, with mean particle size of $12 \mu \mathrm{m}$. Mortars and binder paste specimens were cast keeping the fixed water to binder (cement plus LGP) ratio of 0.40 , while two replacement levels of $10 \%$ and $20 \%$ were employed.

The following conclusions and inferences are drawn from the experimental results and analyses:

(1) LGP is useful in improving the hydration degree and hydration rate at almost all the curing ages; however, the beneficial effect is more pronounced at later stages of strength development (28 days).

(2) The particle size and surface area of LGP greatly affect the pozzolanic reaction in alkaline cementitious matrix. Thus, finer particles increase the reaction rate and help in strength gain in a more effective way than coarser particles. More refined, compact, and uniform microstructural features are also prominent in case of LGP-incorporated pastes.

(3) LGP addition in cement mortars and pastes significantly improves strength and durability owing to reduced porosity, primarily due to the reaction of amorphous silica (present in LGP) with calcium hydroxide (cement hydration product), resulting in the formation of secondary hydrates, and secondarily due to the pore filling effect indebted to the fine LGP particle size.

Although the substitution of cement with LGP leads to improvement in mechanical, durability, and microstructural properties, the deterministic characteristics of LGP particles include particle size/surface area as well as the substitution amount. Up to $20 \%$ (by weight) of cement can be replaced with finer LGP particles (size up to $5 \mu \mathrm{m}$ ), whereas $10 \%$ cement replacement by coarser LGP particles (size up to $12 \mu \mathrm{m}$ ) is deemed useful. This can substantially reduce the cement consumption in mortars and concrete, leading to reduced carbon dioxide emissions and a cleaner environment. For typical building construction and rendering or masonry, the LGP addition is definitely not harmful. However, for certain other specific uses of concretes and mortars, such as radiation shielding, thermally conductive composites for use in structural health monitoring, and lightweight concrete must be carefully studied. Another important study area is the behavior of LGP particles in the presence of nano-materials in cementitious composites: Would the reactivity of LGP increase in the presence of nano-materials? Or would the likelihood of agglomeration of nano-materials inhibit the pozzolanic activity of LGP, and likewise? Such studies need to be further carried out for its deliberation as a permanent cement replacement solution.

Author Contributions: The following statements should be used "conceptualization, I.Y.J.; methodology, I.Y.J. and S.K.K.; formal analysis, A.H.; investigation, S.K.K. and A.H.; resources, I.Y.J.; data curation, S.K.K.; writing-original draft preparation, S.K.K. and A.H.; supervision, I.Y.J.; funding acquisition, I.Y.J."

Funding: This research was supported by Grant (18CTAP-C129830-02) from Technology Advancement Research Program funded by Ministry of Land, Infrastructure and Transport of Korean government.

Conflicts of Interest: The Authors declare that there is no conflict of interest.

\section{References}

1. Spiesz, P.; Rouvas, S.; Brouwers, H.J.H. Utilization of waste glass in translucent and photocatalytic concrete. Constr. Build. Mater. 2016, 128, 436-448. [CrossRef]

2. Korea Environmental Industry \& Technology Institute LCI Database 2015. Available online: http:/ / www. epd.or.kr/en/ (accessed on 12 December 2018).

3. Hanif, A.; Kim, Y.; Lu, Z.; Park, C. Early-age behavior of recycled aggregate concrete under steam curing regime. J. Clean. Prod. 2017, 152, 103-114. [CrossRef]

4. Qiao, F.; Chau, C.K.; Li, Z. Property evaluation of magnesium phosphate cement mortar as patch repair material. Constr. Build. Mater. 2010, 24, 695-700. [CrossRef] 
5. Xu, B.; Ma, H.; Hu, C.; Yang, S.; Li, Z. Influence of curing regimes on mechanical properties of magnesium oxychloride cement-based composites. Constr. Build. Mater. 2016, 102, 613-619. [CrossRef]

6. Péra, J.; Ambroise, J. New applications of calcium sulfoaluminate cement. Cem. Concr. Res. 2004, 34, 671-676. [CrossRef]

7. Parthasarathy, P.; Hanif, A.; Shao, H.; Li, Z. Microstructural and morphological studies of ordinary portland cement paste and fly ash based geopolymer in the presence of chloride ions. In Proceedings of the 71st RILEM Week and ICACMS 2017-International Conference on Advances in Construction Materials and Systems, Chennai, India, 3-8 September 2017.

8. Nuaklong, P.; Sata, V.; Chindaprasirt, P. Influence of recycled aggregate on fly ash geopolymer concrete properties. J. Clean. Prod. 2015, 112, 2300-2307. [CrossRef]

9. $\mathrm{Hu}, \mathrm{C}$. Microstructure and mechanical properties of fly ash blended cement pastes. Constr. Build. Mater. 2014, 73, 618-625. [CrossRef]

10. Khan, M.I.; Siddique, R. Utilization of silica fume in concrete: Review of durability properties. Resour. Conserv. Recyc. 2011, 57, 30-35. [CrossRef]

11. Hu, C.; Li, Z.; Gao, Y.; Han, Y.; Zhang, Y. Investigation on microstructures of cementitious composites incorporating slag. Adv. Cem. Res. 2014, 26, 222-232. [CrossRef]

12. Kim, Y.; Hanif, A.; Usman, M.; Munir, M.J.; Kazmi, S.M.S.; Kim, S. Slag waste incorporation in high early strength concrete as cement replacement: Environmental impact and influence on hydration \& durability attributes. J. Clean. Prod. 2018, 172, 3056-3065. [CrossRef]

13. Ding, J.; Li, Z. Effects of Metakaolin and Silica Fume on Properties of Concrete. ACI Mater. J. 2002, 99, 393-398.

14. Rodríguez de Sensale, G. Strength development of concrete with rice-husk ash. Cem. Concr. Compos. 2006, 28, 158-160. [CrossRef]

15. Lee, H.; Hanif, A.; Usman, M.; Sim, J.; Oh, H. Performance evaluation of concrete incorporating glass powder and glass sludge wastes as supplementary cementing material. J. Clean. Prod. 2018. [CrossRef]

16. Xiao, J. Recycled Aggregate Concrete; Springer Nature (Springer-Verlag GmbH Germany): Berlin, Germany, 2018; ISBN 9783662539859.

17. Hanif, A.; Kim, Y.; Lee, K.; Park, C.; Sim, J. Influence of cement and aggregate type on steam-cured concrete-An experimental study. Mag. Concr. Res. 2017, 69, 694-702. [CrossRef]

18. Ogrodnik, P.; Zegardło, B.; Szelag, M. The Use of Heat-Resistant Concrete Made with Ceramic Sanitary Ware Waste for a Thermal Energy Storage. Appl. Sci. 2017, 7, 1303. [CrossRef]

19. Zegardło, B.; Szelag, M.; Ogrodnik, P. Concrete resistant to spalling made with recycled aggregate from sanitary ceramic wastes-The effect of moisture and porosity on destructive processes occurring in fire conditions. Constr. Build. Mater. 2018, 173, 58-68. [CrossRef]

20. López, V.; Llamas, B.; Juan, A.; Morán, J.M.; Guerra, I. Eco-efficient Concretes: Impact of the Use of White Ceramic Powder on the Mechanical Properties of Concrete. Biosyst. Eng. 2007, 96, 559-564. [CrossRef]

21. Debieb, F.; Kenai, S. The use of coarse and fine crushed bricks as aggregate in concrete. Constr. Build. Mater. 2008, 22, 886-893. [CrossRef]

22. Sharifi, Y.; Afshoon, I.; Firoozjaei, Z.; Momeni, A. Utilization of Waste Glass Micro-particles in Producing Self-Consolidating Concrete Mixtures. Int. J. Concr. Struct. Mater. 2016, 10, 337-353. [CrossRef]

23. Wang, C.-C.; Wang, H.-Y.; Chen, C.-H.; Huang, C. Prediction of Compressive Strength Using Ultrasonic Pulse Velocity for CLSM with Waste LCD Glass Concrete. J. Civil Eng. Archit. 2015, 9. [CrossRef]

24. Kim, S.K.; Kang, S.T.; Kim, J.K.; Jang, I.Y. Effects of particle size and cement replacement of LCD glass powder in concrete. Adv. Mater. Sci. Eng. 2017, 2017. [CrossRef]

25. Kim, K.; Kim, K.; Hwang, J. Characterization of ceramic tiles containing LCD waste glass. Ceram. Int. 2016, 42, 7626-7631. [CrossRef]

26. Tang, C.-W. Properties of fired bricks incorporating TFT-LCD waste glass powder with reservoir sediments. Sustainability 2018, 10, 2503. [CrossRef]

27. Senthil Kumar, K.; Premalatha, P.V.; Baskar, K.; Sankaran Pillai, G.; Shahul Hameed, P. Assessment of Radioactivity in Concrete Made with e-Waste Plastic. J. Test. Eval. 2018, 46, 20160006. [CrossRef]

28. Senthil Kumar, K.; Baskar, K. Development of Ecofriendly Concrete Incorporating Recycled High-Impact Polystyrene from Hazardous Electronic Waste. J. Hazard. Toxic Radioact. Waste 2015, 19, 04014042. [CrossRef] 
29. Kim, K.; Kim, K.; Hwang, J. LCD waste glass as a substitute for feldspar in the porcelain sanitary ware production. Ceramics International 2015, 41, 7097-7102. [CrossRef]

30. Wang, H.-Y. A study of the effects of LCD glass sand on the properties of concrete. Waste Manag. 2009, 29, 335-341. [CrossRef]

31. Her-Yung, W. A study of the engineering properties of waste LCD glass applied to controlled low strength materials concrete. Constr. Build. Mater. 2009, 23, 2127-2131. [CrossRef]

32. Wang, H.Y.; Huang, W.L. Durability of self-consolidating concrete using waste LCD glass. Constr. Build. Mater. 2010, 24, 1008-1013. [CrossRef]

33. Wang, H.; Hou, T. A study of elevated temperatures on the strength properties of LCD glass powder cement mortars. Integr. Waste Manag. 2011. [CrossRef]

34. Lin, K.L.; Huang, W.J.; Shie, J.L.; Lee, T.C.; Wang, K.S.; Lee, C.H. The utilization of thin film transistor liquid crystal display waste glass as a pozzolanic material. J. Hazard. Mater. 2009, 163, 916-921. [CrossRef] [PubMed]

35. Lin, K.L.; Wang, N.F.; Shie, J.L.; Lee, T.C.; Lee, C. Elucidating the hydration properties of paste containing thin film transistor liquid crystal display waste glass. J. Hazard. Mater. 2008, 159, 471-475. [CrossRef] [PubMed]

36. Lin, K.L. Use of thin film transistor liquid crystal display (TFT-LCD) waste glass in the production of ceramic tiles. J. Hazard. Mater. 2007, 148, 91-97. [CrossRef]

37. KS L 5201 Standard Specifications for Ordinary Portlance Cement; Korean Standard Specifications: Seoul, Korea, 1998.

38. Standard Test Method for Sieve Analysis of Fine and Coarse Aggregate. Korean Standards KS F 2502-2010; Korean Standards: Seoul, Korea, 2010.

39. Testing Method for Density and Absorption of Coarse Aggregate. Korean Standards KS F 2503-2007; Korean Standards: Seoul, Korea, 2007.

40. Testing Method for Density and Absorption of Fine Aggregate. Korean Standards KS F 2504-2007; Korean Standards: Seoul, Korea, 2007.

41. Hanif, A.; Kim, Y.; Usman, M.; Park, C. Optimization of Steam-Curing Regime for Recycled Aggregate Concrete Incorporating High Early Strength Cement-A Parametric Study. Materials 2018, 11, 2487. [CrossRef]

42. Hanif, A.; Lu, Z.; Cheng, Y.; Diao, S.; Li, Z. Effects of Different Lightweight Functional Fillers for Use in Cementitious Composites. Int. J. Concr. Struct. Mater. 2017, 11, 99-113. [CrossRef]

43. Hanif, A.; Parthasarathy, P.; Lu, Z.; Sun, M.; Li, Z. Fiber-Reinforced Cementitious Composites Incorporating Glass Cenospheres-Mechanical properties and Microstructure. Constr. Build. Mater. 2017, 154, 529-538. [CrossRef]

44. Li, Z. Advanced Concrete Technology; John Wiley \& Sons, Inc.: Hoboken, NJ, USA, 2011.

45. ASTM C109 Standard Test Method for Compressive Strength of Hydraulic Cement Mortars; American Standard for Testing and Materials: West Conshohocken, PA, USA, 2002.

46. Concrete, Hardened: Accelerated Chloride Penetration. Available online: http://210.42.35.80/G2S/ eWebEditor/uploadfile/20110819235408743.pdf (accessed on 12 December 2018).

47. Kim, Y.; Hanif, A.; Kazmi, S.M.S.; Munir, M.J.; Park, C. Properties enhancement of recycled aggregate concrete through pretreatment of coarse aggregates-Comparative assessment of assorted techniques. J. Clean. Prod. 2018, 191, 339-349. [CrossRef]

48. Hanif, A.; Diao, S.; Lu, Z.; Fan, T.; Li, Z. Green lightweight cementitious composite incorporating aerogels and fly ash cenospheres-Mechanical and thermal insulating properties. Constr. Build. Mater. 2016, 116, 422-430. [CrossRef]

49. Hanif, A.; Parthasarathy, P.; Ma, H.; Fan, T.; Li, Z. Properties Improvement of Fly Ash Cenosphere Modified Cement Pastes Using Nano-Silica. Cem. Concr. Compos. 2017, 81, 35-48. [CrossRef]

50. Van, V.T.A.; Rößler, C.; Bui, D.D.; Ludwig, H.M. Rice husk ash as both pozzolanic admixture and internal curing agent in ultra-high performance concrete. Cem. Concr. Compos. 2014, 53, 270-278. [CrossRef]

51. Winslow, D.N.; Diamond, S. Specific Surface of Hardened Portland Cement Paste as Determined by Small-Angle X-Ray Scattering. J. Am. Ceram. Soc. 1974, 57, 193-197. [CrossRef]

52. Aligizaki, K.K. Pore Structure of Cement-Based Materials: Testing, Interpretation and Requirements; Taylor and Francis: London, UK; New York, NY, USA, 2006; ISBN 9780419228004. 
53. Hu, C.; Li, Z. A review on the mechanical properties of cement-based materials measured by nanoindentation. Constr. Build. Mater. 2015, 90, 80-90. [CrossRef]

54. Hu, C.; Li, Z. Property investigation of individual phases in cementitious composites containing silica fume and fly ash. Cem. Concr. Compos. 2015, 57, 17-26. [CrossRef]

55. Hu, C. Multi-scale Characterization of Concrete. Ph.D. Thesis, Hong Kong University of Science and Technology, Hong Kong, China, August 2014.

56. Scrivener, K.L. Backscattered electron imaging of cementitious microstructures: Understanding and quantification. Cem. Concr. Compos. 2004, 26, 935-945. [CrossRef]

57. Wong, H.S.; Head, M.K.; Buenfeld, N.R. Pore segmentation of cement-based materials from backscattered electron images. Cement and Concrete Research 2006, 36, 1083-1090. [CrossRef]

58. Scrivener, K.L.; Snellings, R.; Lothenbach, B. A Practical Guide to Microstructural Analysis of Cementitious Materials; Taylor \& Francis Group, LLC: Milton, Abingdon, UK, 2016; ISBN 9781498738675.

59. Mehta, P.K.; Monteiro, P.J.M. Concrete: Microstructure, Properties and Materials, 3rd ed.; McGraw-Hill Companies: New York, NY, USA, 2006.

60. Nunes, C.; Slížková, Z.; Stefanidou, M.; Němeček, J. Microstructure of lime and lime-pozzolana pastes with nanosilica. Cem. Concr. Res. 2016, 83, 152-163. [CrossRef]

61. Kosmatka, S.H.; Kerkhoff, B.; Panarase, W.C. Design and Control of Concrete Mixtures, 14th ed.; Portland Cement Association (PCA): Skokie, IL, USA, 2008; ISBN 0-89312-217-3.

62. Chen, X.; Wu, S.; Zhou, J. Influence of porosity on compressive and tensile strength of cement mortar. Constr. Build. Mater. 2013, 40, 869-874. [CrossRef]

63. Allen, A.J.; Thomas, J.J.; Jennings, H.M. Composition and density of nanoscale calcium-silicate-hydrate in cement. Nat. Mater. 2007, 6, 311-316. [CrossRef]

64. Cook, R.A.; Hover, K.C. Mercury porosimetry of hardened cement pastes. Cem. Concr. Res. 1999, $29,933-943$. [CrossRef]

(C) 2018 by the authors. Licensee MDPI, Basel, Switzerland. This article is an open access article distributed under the terms and conditions of the Creative Commons Attribution (CC BY) license (http:/ / creativecommons.org/licenses/by/4.0/). 